\title{
Effect of Grain Size Distribution on Drained Shear Behavior of Poorly Graded Sand
}

\author{
Tong Yu ${ }^{1}$, Hanène Souli ${ }^{2}$, Yoan Péchaud ${ }^{3}$, Jean-Marie Fleureau ${ }^{1 *}$ \\ ${ }^{1}$ Laboratoire de mécanique des Sols, Structures et Matériaux, CNRS UMR 8579, Université Paris Saclay, CentraleSupélec, \\ 8-10 Rue Joliot Curie, Gif-sur-Yvette 91190, France \\ jean-marie.fleureau@centralesupelec.fr; tong.yu@centralesupelec.fr \\ ${ }^{2}$ Laboratoire de Tribologie et Dynamique des Systèmes, CNRS UMR 5513, Université de Lyon, Ecole Nationale \\ d'Ingénieurs de Saint Etienne \\ 58 rue Jean Parot, Saint Etienne Cedex 42023, France \\ hanene.souli@enise.fr \\ ${ }^{3}$ Laboratoire Géomatériaux et Environnement, Université Gustave Eiffel, \\ Marne-la-Vallée Cedex 2 77454, France \\ yoan.pechaud@u-pem.fr \\ * Corresponding author
}

\begin{abstract}
Soil is a widely used material in construction of dams, levees, etc. Its strength is quite significant and has a direct effect on the safety of the structure. Grain size distribution is one of the most important intrinsic parameters that influence the strength of soil. This paper presents a study focused on a series of recombined sands with different fractions $(0,20 \%, 40 \%, 60 \%$, and $100 \%)$ of fine sand $(0-1$ $\mathrm{mm})$ and coarse grains $(1-5 \mathrm{~mm})$. Consolidated drained triaxial tests were performed to study the stress-strain behavior of these different gradings. With increasing fines content in the soil structure, smaller shear strength and larger contraction were obtained. It seems that larger mean particle size $\left(\mathrm{d}_{50}\right)$ contributes to larger strength of the sand. For fines contents lower than the transitional fines content (TFC $=50 \%$ ), with lower $\mathrm{C}_{\mathrm{u}}$, soil strength increases and dilative behavior was enhanced. For fines content larger than the TFC, an opposite trend was observed.
\end{abstract}

Keywords: Grain size distribution, soil strength, fines content, stress-strain behavior, poorly graded sand

\section{Introduction}

Shearing behavior of soil is vital for various applications in construction. Influence of grain size distribution on mechanical response has attracted both engineers' and researchers' interest in the past decades. However, diverse or even opposite conclusions have been drawn in different studies under various experimental conditions. According to [1], gradation makes no difference in the angle of friction at critical state. Similar conclusions were drawn from the simulations of [2], who found that shear strength was independent of grain size distribution. These researchers explained that the constancy of shear strength was due to a subtle compensation of anisotropies. In the study of [3], a significant influence of grain size on peak friction angle, peak dilation angle and stress-dilatancy behavior was found. Moreover, the influence of grain size distribution on the critical state line location in the e-p' plane was unclear [4].

In this study, a series of poorly graded recombined sands, with various percentages of fines and coarse grains was used to study the effect of grain size on shearing behavior. Consolidated drained triaxial tests were conducted. Soil samples were prepared at similar initial relative densities, and consolidated under $100 \mathrm{kPa}$ confining stress.

\section{Materials and Methods}

\subsection{Sand}

The sand from glacial origin used in this study is grey, sub-angular sand $(40 \% 0-1 \mathrm{~mm}, 60 \% 1-5 \mathrm{~mm})$ with a small calcite content. The original sand was divided into two parts, the fine fraction $(0-1 \mathrm{~mm})$ and the coarse grains $(1-5 \mathrm{~mm})$. Recombined sand composed of different fractions of fine and coarse grains were used for the following experiments. The properties of the soil are shown in Fig. 1 and Table 1. 


\subsection{Consolidated Drained Triaxial Tests}

Consolidated drained triaxial tests were conducted. Test samples were prepared by the tamping method in a rigid mould (diameter $99 \mathrm{~mm}$, length $174 \mathrm{~mm}$ ) inside a rubber membrane. Five layers of sand with appropriate moisture content were introduced in the mould, one after another, and each layer was compacted to a target relative density of 0.3 . All the samples were consolidated at $100 \mathrm{kPa}$.
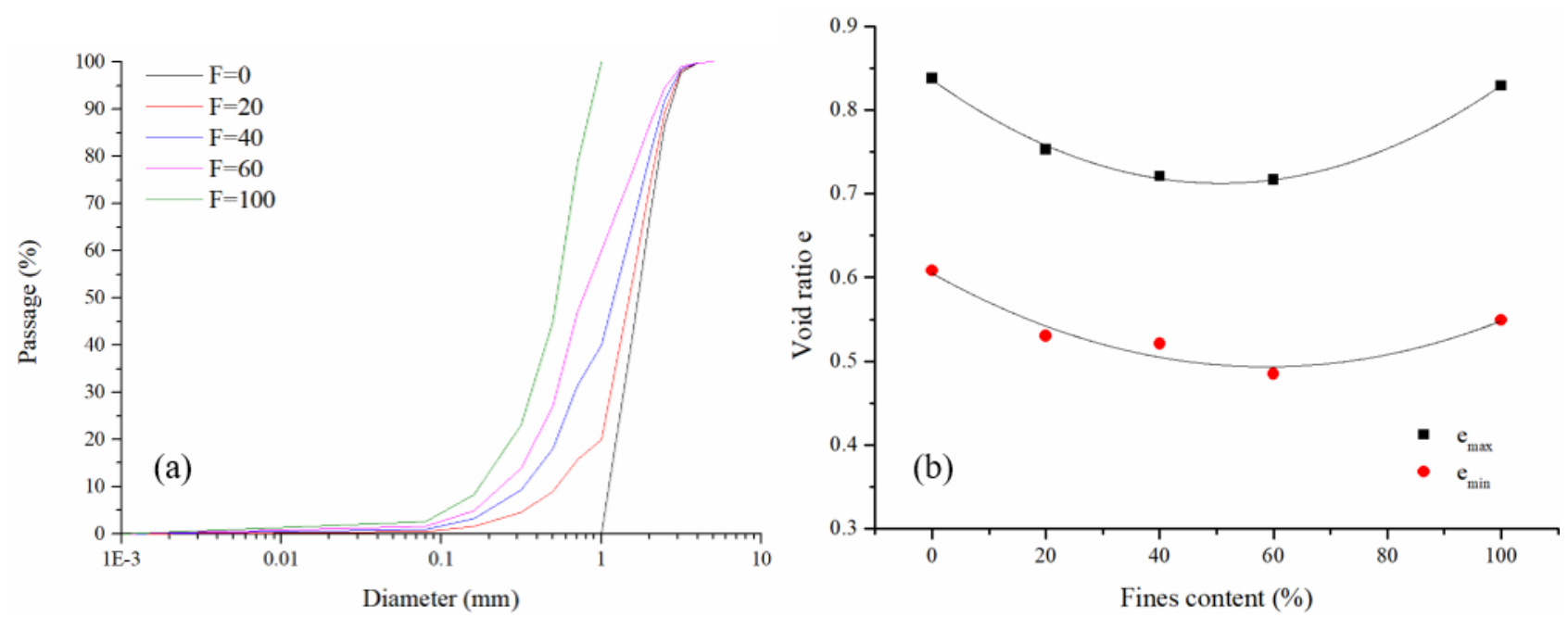

Fig. 1: (a) Grain size distribution of sand (F represents the fines content) (b) $e_{\max }$ and $e_{\min }$ of sands for different fines contents.

Table 1: Properties of sands and test samples.

\begin{tabular}{|c|l|l|l|l|c|l|}
\hline $\begin{array}{c}\text { Fines } \\
\text { content }(\%)\end{array}$ & $\mathrm{d}_{10}$ & $\mathrm{~d}_{50}$ & $\mathrm{C}_{\mathrm{u}}$ & $\mathrm{C}_{\mathrm{c}}$ & $\begin{array}{c}\text { Relative density } \\
\text { after consolidation }\end{array}$ & $\mathrm{B}$ values \\
\hline 0 & 1.14 & 1.71 & 1.66 & 0.93 & 41 & 0.86 \\
\hline 20 & 0.53 & 1.51 & 3.21 & 1.51 & 45 & 0.86 \\
\hline 40 & 0.33 & 1.23 & 4.40 & 0.98 & 67 & 0.92 \\
\hline 60 & 0.25 & 0.77 & 4.04 & 1.14 & 47 & 0.9 \\
\hline 100 & 0.18 & 0.53 & 3.34 & 1.32 & 48 & 0.82 \\
\hline
\end{tabular}

\section{Results and Discussions}

Table 1 shows that $d_{10}$ and $d_{50}$ increase with decreasing fines content. All the sands are poorly graded according to their $\mathrm{C}_{\mathrm{u}}$ and $\mathrm{C}_{\mathrm{c}}$ values. Trends of $\mathrm{e}_{\max }$ and $\mathrm{e}_{\min }$ in Fig. 1(b) are similar to trend of $\mathrm{C}_{\mathrm{u}}$ : they decrease with increasing fines contents from $0 \%$ to around $50 \%$ and then increase for higher fines contents. For these mixtures, the transitional fines content (TFC) is around 50\%. For sands with 0, 20\% and 40\% fines, coarse grains of 1- $5 \mathrm{~mm}$ govern the transmission of forces whereas, for sands with $60 \%$ and $100 \%$ fines, $0-1 \mathrm{~mm}$ particles form the main skeleton.

Fig. 2. shows the stress-strain behavior of the test samples with various fines contents. Fig. 2(a) shows that strength of samples increases with decreasing fines contents except for the test sample with $40 \%$ fines. This is because the sample with $\mathrm{F}=40 \%$ is denser after consolidation compared to the others (Table 1). Maximum strength is around $400 \mathrm{kPa}$ for $\mathrm{F}=0 \%$ and minimum strength is $200 \mathrm{kPa}$ when $\mathrm{F}=100 \%$. The increasing trend of strength with increasing $\mathrm{d}_{50}$ corresponds to the results in [5]. When the fines content is less than the TFC (50\%), with lower $\mathrm{C}_{\mathrm{u}}$, sand presents higher strength and volumetric behavior changes from contraction to dilation. Similar results have been obtained by [6]. When the fines content is larger than the TFC (50\%), an opposite trend is seen because, with lower $\mathrm{C}_{\mathrm{u}}$, soil strength decreases and contractive behavior becomes more obvious. For all the test samples, deviator stress (q) increases rapidly after reaching $1 \%$ axial strain. At around 5\% axial strain, q reaches its maximum value. That is to say, the soil structures of different 
sands start to be destroyed obviously from $1 \%$ axial strain and are completely destroyed after 5\% axial strain. In Fig. 2 (b), at the exception of sample with $\mathrm{F}=0 \%$ that dilates at about $1.5 \%$, all the other samples contract between $1 \%$ and $3 \%$. The contractive behavior increases with increasing fines content.
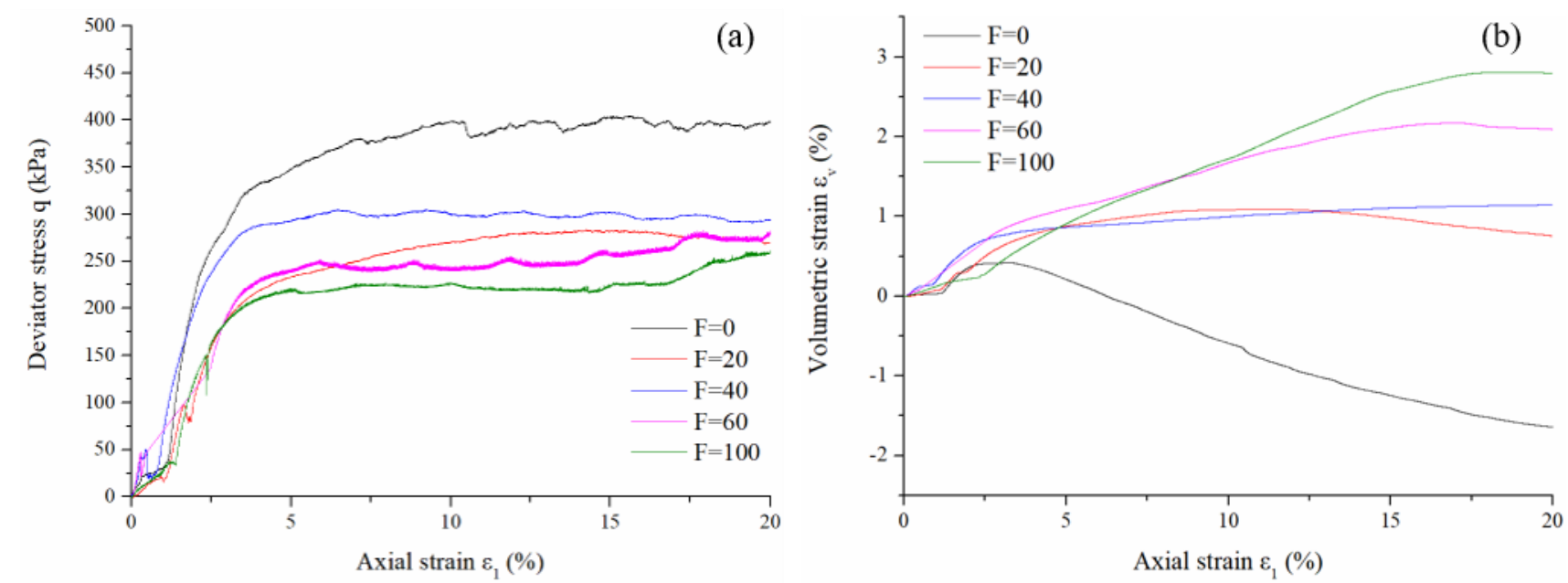

Fig. 2: Stress strain behavior of test samples with different fines contents $(F)$.

\section{Conclusion}

In this study, a series of consolidated drained tests was carried out to study the shear behavior of sands with different coarse and fines fractions. Results show that the strength of sand decreases and contraction increases with increasing fines content and mean grain size $\mathrm{d}_{50}$. On the other hand, the change of strength as a function of $\mathrm{C}_{\mathrm{u}}$ depends on whether fines content is larger or lower than the TFC.

\section{Acknowledgements}

We would like to acknowledge the technical and material support from Solétanche Bachy, and the funding of Chinese Scholarship Council (CSC).

\section{References}

[1] J. Yang and X. D. Luo, "The critical state friction angle of granular materials: does it depend on grading?," Acta Geotech, vol. 13, pp. 535-547, 2018, https://doi.org/10.1007/s11440-017-0581-x.

[2] E. Azéma, S. Linero, N. Estrada and A. Lizcano, "Does modifying the particle size distribution of a granular material (ie, material scalping) alters its shear strength?," in EPJ Web of Conferences, EDP Sciences, 2017, vol. 140, p. 06001.

[3] Y. Deng, Y. Yilmaz, A. Gokce and Ching S. Chang, "Influence of particle size on the drained shear behavior of a dense fluvial sand," Acta Geotech, 2021, https://doi.org/10.1007/s11440-021-01143-7.

[4] M. D. Jiang, Z. X. Yang, D. Barreto and Y. H. Xie "The influence of particle-size distribution on critical state behavior of spherical and non-spherical particle assemblies," Granular Matter, 2018, https://doi.org/10.1007/s10035-018-0850$\mathrm{x}$.

[5] S. Amirpour Harehdasht, M. Karray, M. N. Hussien and M. Chekired, "Influence of particle size and gradation on the stress-dilatancy behavior of granular materials during drained triaxial compression," International Journal of Geomechanics, vol. 17, no. 9, 04017077, 2017.

[6] H. L. Wang, W. H. Zhou, Z. Y. Yin and X. X. Jie, "Effect of grain size distribution of sandy soil on shearing behaviors at soil-structure interface," Journal of Materials in Civil Engineering, vol. 31, no. 10, 04019238, 2019 